\title{
SISTEM PENDUKUNG KEPUTUSAN PEMBERIAN KREDIT ELEKTRONIK PADA PT.PREMIUM CENTRAL INDOSARANA MENGGUNAKAN METODE SIMPLE ADDITIVE WEIGHTING (SAW)
}

\author{
Bagas Setiyaki Wicaksono \\ Staf Pengajar Fakultas Teknik Prodi Teknik Informatika \\ Universitas Pamulang, Tangerang Selatan, Banten \\ Email : bagas.unpamti@gmail.com
}

\begin{abstract}
ABSTRAK
Kendala yang dialami oleh PT. Premium Central Indosarana adalah banyaknya data konsumen karena meningkatnya permintaan akan elektronik dari tahun ke tahun kemungkinan menyebabkan kesulitan bagi perusahan dalam memutuskan siapa pemohon yang layak menjadi penerima kredit.Guna membantu mempercepat dan mempermudah proses pengambilan keputusan, diperlukan suatu bentuk Sistem Pendukung Keputusan (Decision Support System). Tujuannya adalah untuk membantu pengambil keputusan memilih berbagai alternatif keputusan yang merupakan hasil pengolahan informasi-informasi yang diperoleh/tersedia dengan menggunakan model-model pengambilan keputusan. Sistem pendukung keputusan untuk SPK Analisa Kelayakan kredit Elektronik menggunakan metode SAW pada PT. Premium Centra Indosarana dengan berbasis Web menggunakan PHP dan Mysql menghasilkan suatu aplikasi yang memudahkan konsumen dalam mengajukan kredit dan karyawan dalam membuat suatu keputusan dengan mudah.
\end{abstract}

Kata Kunci: Sistem penunjang keputusan pemberian kredit elektronik, metode SAW.

\section{PENDAHULUAN}

PT. Premium central Indosarana (Premium) merupakan perusahaan yang bergerak dibidang retail dengan berbagai macam merk elektronik. Seperti diketahui barang-barang elektronik sudah menjadi kebutuhan masyarakat yang digunakan sebagai alat untuk membantu aktifitas sehari-hari. Hal ini telah terbukti dengan banyaknya barang elektronik yang tersedia dirumah kita (sumber: PT. Premium Central Indosarana).

Premium memberikan kredit kepada setiap calon pembeli elektronik dengan kriteria yang sudah ditentukan perusahaan. Perkembangan teknologi yang semakin pesat sehingga suatu instansi ataupun perusahaan tidak terlepas dari penggunaan komputer sebagai pengolah data. Cara-cara konvensional mungkin juga dapat dilakukan jika jumlah data yang diolah sedikit, tetapi jika jumlah data sangat banyak kemungkinan dapat menyebabkan kesalahan dalam pengolahan data yang mungkin disebabkan oleh kesalahan manusia. Begitu juga pada Premium, banyaknya data konsumen karena meningkatnya permintaan akan elektronik dari tahun ke tahun kemungkinan menyebabkan kesulitan bagi perusahan dalam memutuskan siapa pemohon yang layak menjadi penerima kredit.

Guna membantu mempercepat dan mempermudah proses pengambilan keputusan, diperlukan suatu bentuk Sistem Pendukung Keputusan (Decision Support System). Tujuannya adalah untuk membantu pengambil keputusan memilih berbagai alternatif keputusan yang merupakan hasil pengolahan informasiinformasi yang diperoleh/tersedia dengan menggunakan model-model pengambilan keputusan. Ciri utama, sekaligus keunggulan dari Sistem Pendukung Keputusan (SPK) tersebut adalah kemampuannya untuk menyelesaikan masalah-masalah yang tidak terstruktur. Sistem Pendukung Keputusan dimaksudkan untuk menjadi alat bantu pengambil keputusan dalam hal ini Premium untuk memperluas kapabilitas mereka, namun tidak menggantikan penilaian mereka.

\section{METODE PENELITIAN}

Metode Simple Additive Weighting (SAW) adalah Salah satu metode yang digunakan untuk menyelesaikan masalah dari Fuzzy Multiple Attribute Decision Making ( FMADM ) adalah metode Simple Additive Weighting (SAW) yaitu suatu metode yang digunakan untuk 
mencari alternatif optimal dari sejumlah alternatif dengan kriteria tertentu.

Definisi Metode Simple Additive Weighting $(S A W)$ sering juga dikenal istilah metode penjumlahan terbobot. Konsep dasar metode SAW adalah mencari penjumlahan terbobot dari rating kinerja pada setiap alternatif pada semua atribut (Pahlevy. 2010). Metode SAW membutuhkan proses normalisasi matriks keputusan $X$ ke suatu skala yang dapat diperbandingkan dengan semua rating alternatif yang ada. Formula untuk melakukan normalisasi tersebut adalah sebagai berikut (Kusumadewi, Harjoko, dan Wardoyo. 2006):

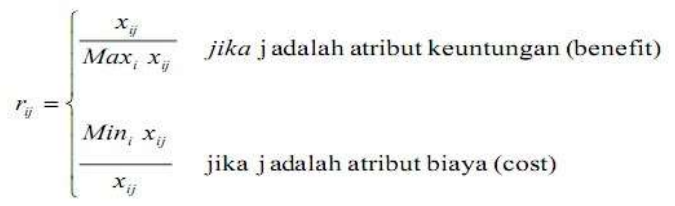

Dimana:

rij = rating kinerja ternormalisasi dari alternatif $\mathrm{Ai}(\mathrm{i}=, 2, \ldots, \mathrm{m})$

Maxi $=$ nilai maksimum dari setiap baris dan kolom. kolom.

Mini $=$ nilai minimum dari setiap baris dan

$\mathrm{Xij}=$ baris dan kolom dari matriks.

Formula untuk mencari nilai preferensi untuk setiap alternatif (Vi):

$$
\mathrm{V}_{\mathrm{i}}=\sum_{\mathrm{j}=1}^{\mathrm{n}} \mathrm{w}_{\mathrm{j}} \mathrm{r}_{\mathrm{ij}}
$$

Dimana:

$\mathrm{Vi}=$ Nilai akhir dari alternatif

$\mathrm{Wi}=$ Bobot yang telah ditentukan

Rij $=$ Normalisasi matriks.

\section{Langkah Penggunaan Metode SAW}

a. Menentukan kriteria-kriteria yang akan dijadikan acuan dalam pengambilan keputusan.

b. Menentukan rating kecocokan setiap alternatif pada setiap kriteria.

c. Membuat matriks keputusan berdasarkan kriteria, kemudian melakukan normalisasi matriks berdasarkan persamaan yang disesuaikan dengan jenis atribut (atribut keuntungan ataupun atribut biaya) sehingga diperoleh matriks ternormalisasi R. d. Hasil akhir diperoleh dari proses perankingan yaitu penjumlahan dari perkalian matriks ternormalisasi $\mathrm{R}$ dengan vektor bobot sehingga diperoleh nilai terbesar yang dipilih sebagai alternatif terbaik sebagai solusi (Henry. 2009).

\section{PEMBAHASAN}

\section{Sistem Usulan}

Sistem informasi berbasis web dalam analisa kelayakan kredit pada PT. Premium Centra Indosarana merupakan suatu sistem yang dirancang untuk memberikan analisa kelayakan kredit dengan menggunakan web.

Dalam sistem yang dikembangkan, penulis menitikberatkan racangan usulan untuk proses analisa kelayakan kredit dengan menggunakan web, oleh karena itu penulis langsung menjabarkan prosesnya sebagai berikut:

1. Calon konsumen melakukan pengajuan kredit/registrasi di sistem lalu melakukan login.

2. Setelah melakukan login konsumen bisa melakukan pengajuan kredit secara online lalu mencetak bukti pengajuan kredit.

3. Karyawan melakukan login pada sistem. Karyawan bisa melihat dan mengelola data konsumen yang telah melakukan pengajuan kredit secara online.

4. Karyawan yang sudah login bisa melakukan analisis data dan pembuatan keputusan untuk menentukan kelayakan pemeberian kredit terhadap konsumen.

\section{Tujuan dan Sasaran}

Dengan mengacu pada analisa dan pemahaman pada sistem berjalan didapatkan beberapa masalah, dengan usulan diharapkan dapat mengatasi permasalahan tersebut dan dengan adanya sistem usulan yang penulis kemukakan akan memberikan analisa kelayakan kredit yang jauh lebih baik pada sistem sebelumnya.

1) Tujuan

Tujuan dari perkembangan perancangan sistem informasi penunjang keputusan kelayakan kredit berbasis web adalah sebagai berikut:

a. Meningkatkan kemudahan dalam melakukan pengolahan data kelayakan kredit agar dapat memberikan hasil konfirmasi pada konsumen, karyawan, dan pimpinan PT. Premium Centra Indosarana. 
b. Mempermudah pihak karyawan dalam pembuatan laporan kepada Pimpinan PT. Premium Centra Indosarana.

\section{2) Sasaran.}

Sasaran yang hendak dicapai dalam analisa perancangan sistem informasi penunjang keputusan kelayakan kredit berbasis web adalah sebagai berikut:

a. Aplikasi sistem harus mendukung tujuan utama penunjang keptusan pengolahan analisa kelayakan kredit. b. Memberikan kinerja yang efektif dan efisien dalam melakukan pengolahan analisa kelayakan kredit.

c. Sistem dapat menyimpan dan mengolah data menjadi informasi yang sangat membantu dan memberikan informasi yang tepat.

Adapun use case diagram usulannya adalah sebagai berikut:

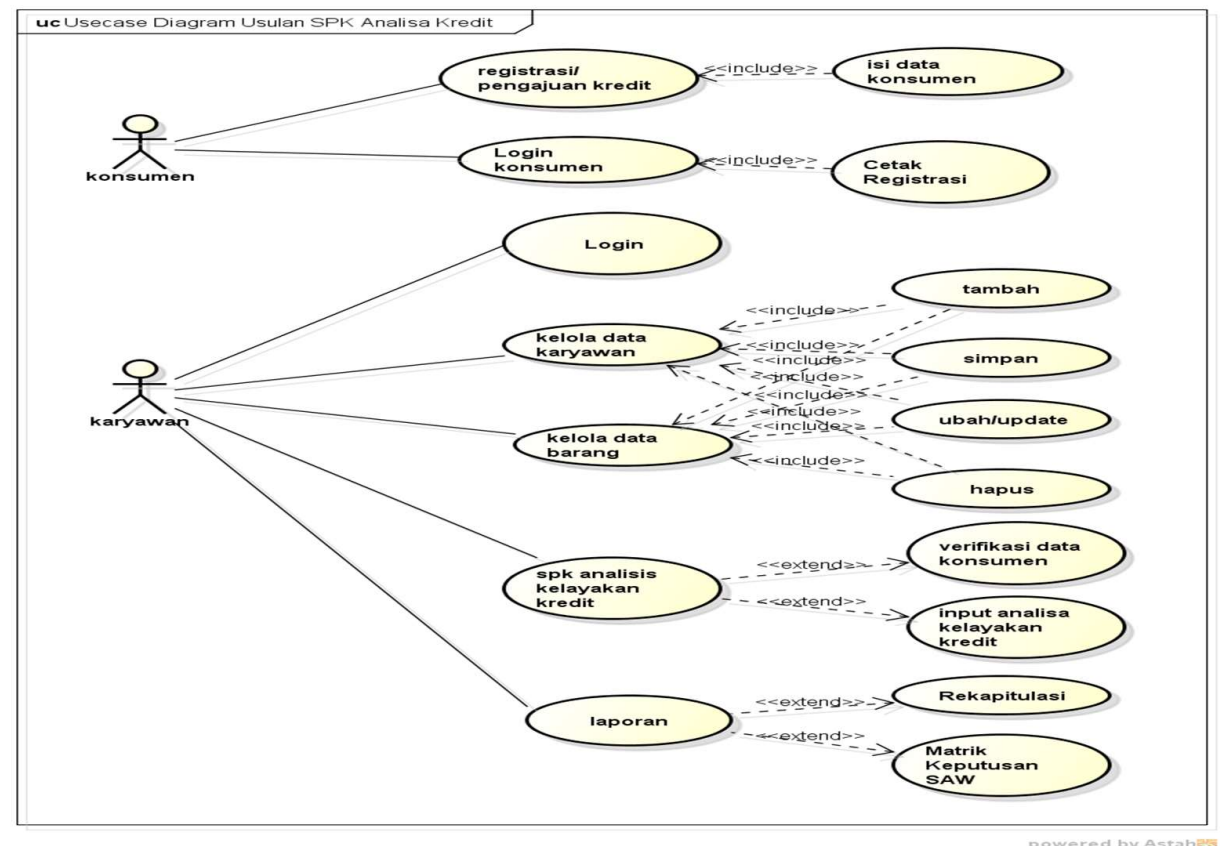

Gambar 3.1 Use Case Digram Usulan SPK Analisa Kredit

\subsection{Pengujian Sistem}

Pada tahap akhir dari pembuatan aplikasi analisis kredit pada PT. Premium Central Indosarana ini akan dilakukan pengujian terhadap sistem yang ada.

Penentuan konsumen kredit pada PT. Premium Central Indosarana berdasarkan pada penilaian kredit Credrit analyst yaitu kepribadian konsumen, kemampuan membayar konsumen dan kondisi ekonomi konsumen. Oleh karena itu penulis menggunakan kriteria penentuan pemberian kredit yang digunakan oleh perusahaan ini yaitu Character (kepribadian), Capacity (kemampuan), Capital (modal), Kepemilikan rumah, dan Masa kerja. Berikut tahapan pengujian menggunakan metode SAW:

1. Melakukan normalisasi matriks dengan cara menghitung nilai rating ternormalisasi
( $\left.\mathrm{r}_{\mathrm{ij}}\right)$ dari altenatif $\mathrm{A}_{\mathrm{i}}$ pada atribut $\mathrm{C}_{\mathrm{j}}$ berdasarkan persamaan yang disesuaikan dengan jenis atribut (atribut keuntungan/benefit $=$ Maksimum atau atribut biaya $/ \operatorname{cost}=$ Minimum). Apabila berupa atribut keuntungan maka nilai crips $\left(\mathrm{X}_{\mathrm{ij}}\right)$ dari setiap kolom atribut dibagi dengan nilai crips $\operatorname{Max}\left(\operatorname{Max} \mathrm{X}_{\mathrm{ij}}\right)$ dari tiap kolom, sedangkan untuk atribut biaya nilai crips Min $\left(\mathrm{X}_{\mathrm{ij}}\right)$ dari tiap kolom.

2. Perhitungan normalisasi matrik (R) dengan atribut benefit untuk kriteria $\mathrm{C} 1, \mathrm{C} 2, \mathrm{C} 3$, C4, C5 sebagai berikut :

Rumus:

$$
\begin{aligned}
& R i j=\quad X_{i j} \\
& \text { Max. Xij }
\end{aligned}
$$


3. Melakukan proses penilaian dengan cara mengalikan matriks ternormalisasi (R) dengan nilai bobot (W)

$\mathrm{R}=\frac{0,37}{1}\left[\begin{array}{llll}1 & 0,4 & 0,38 & 0,25 \\ 0,5\end{array}\left[\begin{array}{llll}1 & 0,5 & 1 & 1 \\ 1 & 1 & 0,38\end{array}\right]\right.$

4. Terakhir menentukan nilai untuk setiap alternatif (Vi) dengan menjumlahkan hasil kali antara matriks ternormalisasi (R) dengan nilai bobot (W). Penjumlahan hasil kali matriks ternormalisasi menghasilkan angka sebagai berikut:

Rumus: $\quad \mathrm{V}_{\mathrm{i}}=\sum_{\mathrm{j}=1}^{\mathrm{n}} \mathrm{w}_{\mathrm{j}} \mathrm{r}_{\mathrm{ij}}$

Dimana:

$\mathrm{Vi}=$ Nilai akhir dari alternatif

$\mathrm{Wj}=$ Bobot yang telah ditentukan

$\mathrm{rij}_{\mathrm{j}}=$ Normalisasi matriks $(\mathrm{R})$

Vektor

bobot

$[\mathrm{W}]=\{20,25,25,20,10\}$

Penyelesaian:

$\mathrm{V} 1=(20)(1)+(25)(0,4)+(25)(0,38)+(20)(0$, $25)+(10)(0,37)=48.2$

$\mathrm{V} 2=(20)(1)+(25)(0,8)+(25)(0,5)+(20)(1)+$

$(10)(1)=82.5$

$\mathrm{V} 3=(20)(1)+(25)(1)+(25)(1)+(20)(0,38)+($ $10)(0,5)=82,6$

Dari perhitungan tersebut diambil kesimpulan nilai yang dinyatakan layak adalah 50-100 maka V2 Andri Saputra (A2) dan V3 Soraya (A3), dinyatakan layak untuk kredit.

\section{KESIMPULAN}

Berdasarkan hasil penelitian dan analisa SPK Kelayakan kredit Elektronik menggunakan metode SAW pada PT. Premium Centra Indosarana maka dapat diambil kesimpulan:

a. Sistem pendukung keputusan untuk SPK Analisa Kelayakan kredit Elektronik menggunakan metode SAW pada PT. Premium Centra Indosarana dengan menggunakan PHP dan Mysql menghasilkan suatu aplikasi yang memudahkan konsumen dalam mengajukan kredit dan karyawan dalam membuat suatu keputusan dengan mudah.

b. Perangkingan alternatif dari hasil perhitungan bobot nilai konsumen dengan menggunakan metode SAW menghasilkan suatu keputusan yang akurat dan sesuai dengan kriteria yang diharapkan.

c. Kriteria penentuan pemberian kredit yang digunakan yaitu Character (kepribadian), Capacity (kemampuan), Capital (modal), Kepemilikan rumah, dan Masa kerja menghasilkan penilaian konsumen yang sesuai dengan kebutuhan yang diperlukan oleh pihak PT. Premium Centra Indosarana.

\section{SARAN}

Penulis menyadari bahwa masih banyaknya kekurangan dalam pembuatan skripsi ini, Maka dari itu berharap sistem ini dapat dikembangkan lebih baik lagi dan mendapatkan saran yang lebih baik lagi untuk penulis. Adapun saran dari penulis adalah

a. Sistem dan aplikasi yang penulis usulkan pada skripsi ini dapat dikembangkan dengan penambahan kriteria, variabel atau dengan metode lain agar hasilnya lebih baik dan akurat.

b. Implementasi dari Sistem Pendukung Keputusan Untuk Kelayakan Kredit Elektronik Menggunakan Metode SAW Pada PT. Premium Centra Indosarana berbasis web ini belum terlaksana dan belum terlihat hasil kepuasannya karena masih memerlukan persetujuan dari pihak perusahaan.

\section{DAFTAR PUSTAKA}

[1] Abdul Kadir. (2010). Pengenalan Sistem Informasi, Andi, Yogyakarta.

[2] Agus Mulyanto. (2009). Sistem Informasi Konsep dan Aplikasi. Pustaka Pelajar. Yogyakarta.

[3] A.S, Rossa. (2014). Rekayasa Perangkat Lunak Terstruktur Dan Berorientasi Objek. Bandung: Informatika.

[4] Al-Bahra bin Ladjamudin. (2008). Analisis dan Desain Sistem Informasi. Yogyakarta : Graha Ilmu.

[5] Connolly, Thomas M., Begg, Carolyn E. (2010). Database System: a Practical Approach to Design Implementation and Management. USA: Pearson Education.

[6] Dennis, Alan(2012).Systems Analys \& Design With UML version 2.0 : Fourth Edition.. Wiley Global Education. 
[7] Elmasri, R., Navathe, B. S. (2010). Fundamental of Database Systems. California: The Banjamin/Cummings Company.

[8] Hasan, I. (2010). Pokok - Pokok Materi Teori Pengambilan Keputusan. Jakarta : Ghalia Indonesia.

[9] Kusumadewi, Sri., Hartati, S., Harjoko, A., dan Wardoyo, R. (2006). Fuzzy Multi-Attribute Decision Making (FUZZY MADM).Yogyakarta: Penerbit Graha Ilmu.

[10] McLeod, Raymond. (2008). Management Information System, $10^{\text {th }}$ ed. Jakarta: Penerbit Salemba empat.

[11] Pressman, R.S. (2010), Software Engineering : a practitioner's approach, McGraw-Hill, New York. 